\title{
Redox Polymers Incorporating Pendant 6-Oxoverdazyl and Nitronyl Nitroxide Radicals
}

Michael Anghel, ${ }^{1,2, \dagger}$ François Magnan, ${ }^{1,2, \dagger}$ Sara D. Catingan, ${ }^{1,2,3}$ Matthew A. McCready, ${ }^{2,3}$ Elaheh Aawani, ${ }^{2,3}$ Victor Wong, ${ }^{2,3}$ Deepa Singh, ${ }^{2,3}$ Giovanni Fanchini, ${ }^{1,2,3} *$ and Joe B. Gilroy ${ }^{1,2} *$

${ }^{\dagger}$ These authors contributed equally.

${ }^{1}$ Department of Chemistry and ${ }^{2}$ The Centre for Advanced Materials and Biomaterials Research (CAMBR), The University of Western Ontario, London, ON, Canada, N6A 5B7. ${ }^{3}$ Department of Physics and Astronomy, The University of Western Ontario, London, ON, Canada, N6A 3K7.

Correspondence to G. Fanchini (E-mail: gfanchin@uwo.ca) or J. B. Gilroy (E-mail: joe.gilroy@uwo.ca)

\begin{abstract}
Polymers comprised of redox-active organic radicals have emerged as promising materials for use in a variety of organic electronics, including fast-charging batteries. Despite these advances, relatively little attention has been focused on the diversification of the families of radicals that are commonly incorporated into polymer frameworks, with most radical polymers being comprised of nitroxide radicals. Here, we report two new examples prepared via ring-opening methathesis polymerization containing 6-oxoverdazyl and nitronyl nitroxide radicals appended to their backbones. The polymerization reaction and optoelectronic properties were explored in detail, revealing high radical content and redox activity that may be advantageous for their use as semiconducting thin films. Initial studies revealed that current-voltage curves obtained from thin films of the title polymers exhibited memory effects making them excellent candidates for use in resistive memory applications.
\end{abstract}

\section{KEYWORDS}

Redox polymers, stable radical polymers, 6-oxoverdazyl, nitronyl nitroxide, ring-opening metathesis polymerization, polymer thin films 


\section{INTRODUCTION}

Redox polymers ( $a k a$ redox-active polymers) are a class of macromolecules that are able to lose (oxidation) and/or gain (reduction) electrons, affording a wide range of tunable properties. ${ }^{1}$ Members of this unique class of polymers generally incorporate $\pi$-conjugated organics (e.g., 1 and 2), ${ }^{2,3}$ transition metal complexes (e.g., $\mathbf{3}$ and $\left.\mathbf{4}\right),{ }^{4,5}$ or stable radicals (e.g., 5 and $\left.\mathbf{6}\right)^{6,7}$ either as part of or appended to a polymer backbone. Redox polymers have found use in a variety of applications, for example: as actuators ${ }^{8}$ in redox-active capsules for molecular cargo delivery, ${ }^{9}$ and as charge-storage materials in batteries. ${ }^{10}$
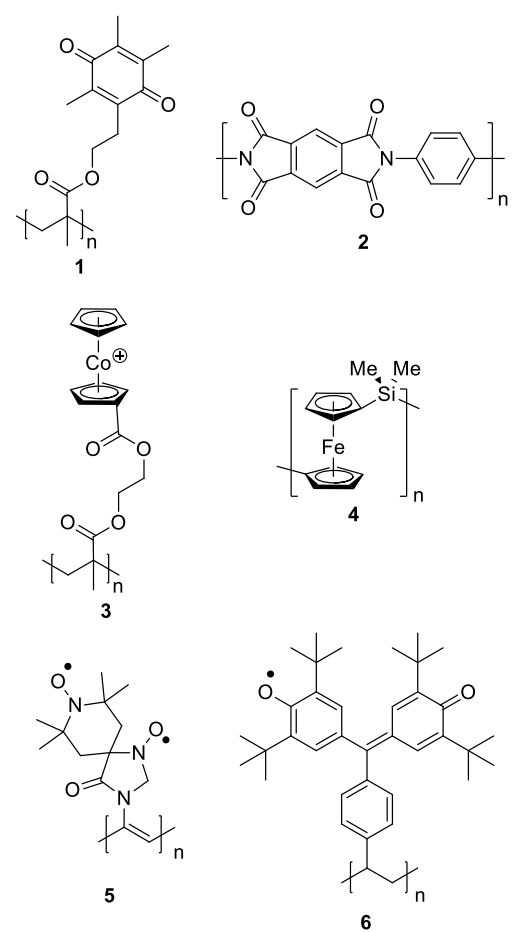

The stable radical polymer field ${ }^{6}$ has gained momentum over the past two decades, primarily due to the rapid charge-discharge characteristics of stable radical batteries. ${ }^{6 a,} 10 a, 11$ Most studies have focused on poly(2,2,6,6-tetramethylpiperidinyloxy methacrylate) 7 due to its desirable properties and ready accessibility. ${ }^{11-12}$ More recently, fundamental studies of the conductivity of polymers $7^{13}$ and $\mathbf{8}^{14}$ have garnered significant attention and demonstrated the 
efficacy of structural modification as a tool for property modulation. Given these findings it is perhaps surprising that radicals such as nitronyl nitroxides ${ }^{15}$ and 6-oxoverdazyls ${ }^{16}$ have received relatively little attention despite their ambipolar redox properties. ${ }^{17}$ With that said, nitronyl nitroxide polymer $\mathbf{9}$ has shown utility as both the anode and cathode material in organic radical batteries $^{15 \mathrm{~d}}$ and our group has recently shown that 6-oxoverdazyl polymer $\mathbf{1 0}$ offers a unique combination of ultrathin film-forming and switchable conductivity properties that led to its use in resistive memory devices (i.e., memristors). ${ }^{18}$
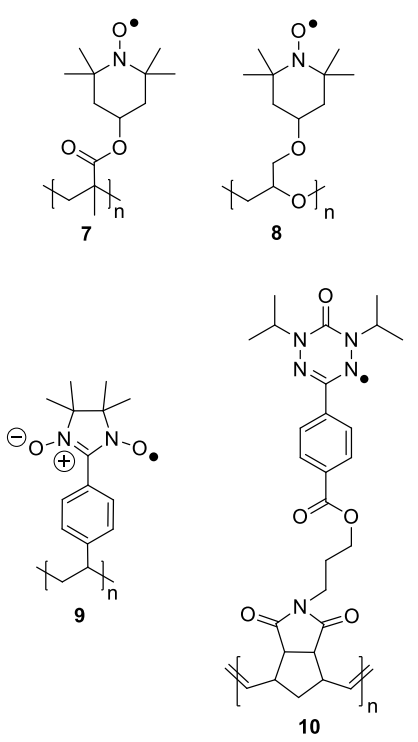

Given the rejuvenated interest in the study of radical polymers as semiconducting materials and the promise of examples exhibiting ambipolar redox properties in a variety of applications, we report the synthesis, characterization, and thin-film properties of two new polymers prepared using a radical-tolerant ring-opening metathesis polymerization (ROMP) reaction. Such structural elaboration is essential for further progression of the stable radical polymer research field and the applications it targets. 


\section{EXPERIMENTAL SECTION}

\section{General Considerations}

Reactions and manipulations were carried out under an $\mathrm{N}_{2}$ atmosphere using standard Schlenk techniques unless otherwise stated. Reagents were purchased from Sigma-Aldrich or Alfa-Aesar and used as received unless specified. Solvents were purchased from Caledon Laboratories, dried using an Innovative Technologies Inc. solvent purification system, collected under vacuum, and stored under an $\mathrm{N}_{2}$ atmosphere over $4 \AA$ molecular sieves prior to use. 2,4Diphenylcarbonohydrazide 11, ${ }^{19} \mathrm{~N}$-[3-hydroxylpropyl]-cis-5-norbornene-exo-2,3-dicarboximide $\mathbf{1 4},{ }^{20}$ 2,3-bis(hydroxyamino)-2,3-dimethylbutane $\mathbf{1 7},{ }^{21}$ and the 3-bromopyridine derivative of Grubbs' third generation catalyst (Grubbs III) ${ }^{22}$ were prepared according to published procedures.

NMR spectra were recorded on $400 \mathrm{MHz}\left({ }^{1} \mathrm{H}: 400.1 \mathrm{MHz}\right)$ or $600 \mathrm{MHz}\left({ }^{13} \mathrm{C}\left\{{ }^{1} \mathrm{H}\right\}: 150.7\right.$ MHz) Varian INOVA instruments at $25{ }^{\circ} \mathrm{C} .{ }^{1} \mathrm{H}$ NMR spectra were referenced to residual DMSO- $d_{5}(\delta=2.50)$ and ${ }^{13} \mathrm{C}\left\{{ }^{1} \mathrm{H}\right\}$ NMR spectra were referenced to DMSO- $d_{6}(\delta=39.5)$. Mass spectra were recorded in positive-ion mode using a high-resolution Thermo Scientific DFS (Double Focusing Sensor) mass spectrometer using electron impact ionization. FT-IR spectra were recorded on a PerkinElmer Spectrum Two instrument using an attenuated total reflectance accessory. UV-vis absorption spectra were recorded on a Cary 5000 UV-Vis-NIR spectrophotometer between 200 and $800 \mathrm{~nm}$. Molar extinction coefficients were determined from the slope of a plot of absorbance against concentration based on absorption data of four different concentrations. Elemental analyses were conducted using a vario ISOTOPE cube by the Analytical Services Laboratory in the Biotron Facility at the University of Western Ontario. 


\section{Gel Permeation Chromatography}

GPC experiments were conducted in chromatography-grade THF at concentrations of $5 \mathrm{mg} \mathrm{mL}^{-1}$ using a Viscotek GPCmax VE 2001 GPC instrument equipped with an Agilent PolyPore guard column (PL1113-1500) and two sequential Agilent PolyPore GPC columns packed with porous poly(styrene-co-divinylbenzene) particles (MW range: 200-2,000,000 $\mathrm{g} \mathrm{mol}^{-1}$; PL1113-6500) regulated at a temperature of $30^{\circ} \mathrm{C}$. Signal responses were measured using a Viscotek VE 3580 refractive index detector, and molecular weights were determined by comparison of the maximum refractive index response with a calibration curve (10 points, $1500-786,000 \mathrm{~g} \mathrm{~mol}^{-1}$ ) established using monodisperse polystyrene standards purchased from Viscotek.

\section{Electron Paramagnetic Resonance Spectroscopy}

EPR spectra were recorded for $c a .100 \mu \mathrm{M}$ degassed $\mathrm{CH}_{2} \mathrm{Cl}_{2}$ solutions (three freeze-pump-thaw cycles) of the analytes in $0.4 \mathrm{~mm}$ quartz tubes using a JEOL JES-FA200 EPR spectrometer. Measurements were made at $25{ }^{\circ} \mathrm{C}$ and $g$-factors were referenced relative to a built-in $\mathrm{Mn}^{2+}$ marker within the resonant cavity of the instrument. Monomer simulations were performed using a least-square fitting method using the Easyspin program, ${ }^{23}$ which is an add-on to the MATLAB software package.

Quantitative experiments were performed as follows: approximately $5 \mathrm{mg}$ of 2,2,6,6Tetramethylpiperidine 1-oxyl (TEMPO) and the polymer samples to be analyzed were loaded into capillary tubes inside a glove box. In our case, we filled the capillary tubes to a depth of 1 $\mathrm{cm}$ and packed the solid by tapping it gently on a lab bench, before determining an accurate mass. It is essential that the density, shape, size, and position of the sample in the resonant cavity of the instrument remain constant. The TEMPO sample was then loaded into the instrument and the resonant cavity tuned before a spectrum was recorded. The polymer samples were analyzed 
immediately after the TEMPO spectrum was acquired, ensuring that the sample position was identical. The spectra of the polymers were collected without re-tuning the resonant cavity under the same conditions used to collect the spectrum of TEMPO. Working under the assumption that each TEMPO molecule contributes one unpaired electron, the number of unpaired electrons present in the radical polymers can be determined by comparison of the integrations of the spectra collected after correction for the molecular weight of the radicals involved.

\section{Thermal Analysis}

Thermal degradation studies were performed using a TA Instruments Q50 TGA instrument. Polymer samples were placed in a platinum pan and heated at a rate of $10{ }^{\circ} \mathrm{C} \min ^{-1}$ from 20-1000 ${ }^{\circ} \mathrm{C}$ under a flow of $\mathrm{N}_{2}\left(60 \mathrm{~mL} \mathrm{~min}^{-1}\right)$. Differential scanning calorimetry studies were performed using a TA Instruments DSC Q20. Polymer samples were placed in an aluminum Tzero pan and subjected to three heating cooling cycles (16: 20-190 ${ }^{\circ} \mathrm{C} ; \mathbf{2 1}$ : $20-150{ }^{\circ} \mathrm{C}$ ) at a rate of $10{ }^{\circ} \mathrm{C} \min ^{-1}$ under a flow of $\mathrm{N}_{2}\left(50 \mathrm{~mL} \mathrm{~min}{ }^{-1}\right)$. The second heating/cooling cycles are reported.

\section{Cyclic Voltammetry}

Cyclic voltammetry experiments were performed using a Bioanalytical Systems Inc. (BASi) Epsilon potentiostat and analyzed using BASi Epsilon software. Electrochemical cells consisted of a three-electrode setup including a glassy carbon working electrode, platinum wire counter electrode and silver wire pseudo reference electrode. Experiments were run at scan rates of 50-1000 $\mathrm{mV} \mathrm{s}^{-1}$ in degassed $\mathrm{CH}_{2} \mathrm{Cl}_{2} / \mathrm{CH}_{3} \mathrm{CN}(50: 50 \mathrm{v} / \mathrm{v})$ solutions of the analyte $(\sim 1 \mathrm{mM})$ and supporting electrolyte $\left(0.1 \mathrm{M}\left[n \mathrm{Bu}_{4}\right]\left[\mathrm{PF}_{6}\right]\right)$. Cyclic voltammograms were referenced against an internal standard ( $\sim \mathrm{mM}$ ferrocene) and corrected for internal cell resistance using the BASi Epsilon software. 


\section{Thin-Film Preparation and Electrical Conductivity Measurements}

Thin films of varying thickness were spun from radical polymers $\mathbf{1 6}$ and $\mathbf{2 1}$ and memory effects on their electrical properties were measured. Thin-film deposition was carried out in a Nexus II (Vacuum Atmospheres Co.) glove box incorporating an ultra-high vacuum (UHV) chamber with a thermal evaporator complete with a thickness monitor (STM, Sycom). Moisture and oxygen contents were below $1 \mathrm{ppm}$ and $10 \mathrm{ppm}$, respectively, during the entire thin-film deposition process. Polymers were dissolved at $10 \mathrm{mg} \mathrm{mL}^{-1}$ in anhydrous chlorobenzene. Solutions were filtered in a syringe filter $(0.8 \mu \mathrm{m}$ pore size $)$. Glass slides with pre-patterned indium tin-oxide (ITO) contacts (75 $\Omega$ / square sheet resistance, Millipore-Sigma) were used as substrates. A KW4A spin coater (Chemat Technologies Inc.) was used to spin a set of thin films from both polymers by varying the spin speed in the 650 to $4000 \mathrm{rpm}$ speed range. No continuous film could be obtained above 2000 rpm from polymer 21 .

To gain insight into the memory effects in the current-voltage (I-V) electrical properties of our polymers, room temperature electrical measurements were performed in vacuum in a sandwich configuration. To complete the sandwich structure, samples were transferred in the aforementioned UHV chamber directly accessible from the glove box and bilayer metal contacts (comprised of a $20 \mathrm{~nm}$ thick calcium film in contact to the polymer, with an overlying $80 \mathrm{~nm}$ film on it) were added. Metal contacts were deposited orthogonally with respect to the prepatterned ITO electrodes and were grown through a shadow mask. The thermal evaporation temperature was kept below $50{ }^{\circ} \mathrm{C}$ during the entire evaporation process. Samples were contacted through Signatone S-750 probes. For both sets of samples (polymer 16 and 21, respectively) memory effects were tested as follows: voltage was initially ramped up from 0 to $+\mathrm{V}_{0}$ (conventionally positive at the ITO contact). Then, the voltage was decreased from $+\mathrm{V}_{0}$ to 
$-\mathrm{V}_{0}$ and subsequently increased again to $+\mathrm{V}_{0}$. Maximum voltage was optimized at $\mathrm{V}_{0}=1.5 \mathrm{~V}$ and $2.0 \mathrm{~V}$ for polymer $\mathbf{1 5}$ and $\mathbf{2 1}$, respectively. All electrical measurements were recorded using a computer automated Keithley 2400 source meter with $10 \mathrm{mV}$ scan step. Multiple cycles were performed to ensure measurement reproducibility. Measurements and comparisons discussed below refer to polymer $\mathbf{1 6}$ and $\mathbf{2 1}$ samples at comparable (30 $\mathrm{nm} \pm 10 \%)$ thickness.

Tapping-mode atomic force microscopy (AFM) was performed using a Witec Alpha300S AFM system. Film thicknesses were measured by scratching the sample surface with a plastic toothpick and recording AFM profiles around the resulting step at the film edge. Root-meansquared (RMS) roughness data were determined from the film-coated part of the AFM images.

\section{Synthetic Procedures}

Tetrazane 12. To a refluxing solution of 2,4-diphenylcarbonohydrazide $(1.58 \mathrm{~g}, 6.54 \mathrm{mmol})$ in $\mathrm{MeOH}(25 \mathrm{~mL})$ was added dropwise over $1.5 \mathrm{~h}$ a solution of 4-carboxybenzaldehyde $(0.97 \mathrm{~g}$, $6.5 \mathrm{mmol})$ and $\mathrm{NaOAc}(0.52 \mathrm{~g}, 6.4 \mathrm{mmol})$ in $\mathrm{MeOH}(40 \mathrm{~mL})$. The solution was stirred at reflux overnight, then cooled to room temperature. Following acidification with a minimal amount of conc. $\mathrm{HCl}$ and removal of volatiles in vacuo, the resulting residue was slurried in $\mathrm{H}_{2} \mathrm{O}$, filtered and rinsed with additional $\mathrm{H}_{2} \mathrm{O}$ to afford the title product as a white powder upon drying. Yield $=$ 1.89 g, 98\%. M.p.: $>250{ }^{\circ} \mathrm{C} .{ }^{1} \mathrm{H}$ NMR (400.1 MHz, DMSO- $\left.d_{6}\right): 12.98$ (bs, $\left.1 \mathrm{H}, \mathrm{COOH}\right), 7.92(\mathrm{~d}$, $\left.{ }^{3} J_{\mathrm{HH}}=8 \mathrm{~Hz}, 2 \mathrm{H}, \operatorname{aryl} \mathrm{CH}\right), 7.66\left(\mathrm{~d},{ }^{3} J_{\mathrm{HH}}=8 \mathrm{~Hz}, 2 \mathrm{H}, \operatorname{aryl} \mathrm{CH}\right), 7.60\left(\mathrm{~d},{ }^{3} J_{\mathrm{HH}}=9 \mathrm{~Hz}, 4 \mathrm{H}, \operatorname{aryl}\right.$ $\mathrm{CH}), 7.33\left(\mathrm{t},{ }^{3} J_{\mathrm{HH}}=8 \mathrm{~Hz}, 4 \mathrm{H}, \operatorname{aryl} \mathrm{CH}\right), 7.08\left(\mathrm{t},{ }^{3} J_{\mathrm{HH}}=7 \mathrm{~Hz}, 2 \mathrm{H}, \operatorname{aryl~CH}\right), 6.49\left(\mathrm{~d},{ }^{3} J_{\mathrm{HH}}=9 \mathrm{~Hz}\right.$, $2 \mathrm{H}, \mathrm{NH}), 5.48\left(\mathrm{t},{ }^{3} J_{\mathrm{HH}}=9 \mathrm{~Hz}, 1 \mathrm{H}, \mathrm{CH}\right) .{ }^{13} \mathrm{C}\left\{{ }^{1} \mathrm{H}\right\}$ NMR (150.7 MHz, DMSO- $\left.d_{6}\right): 167.0,157.0$, 142.7, 142.5, 130.6, 129.3, 128.0, 127.2, 123.4, 121.1, 72.5. FT-IR (ATR): 3228 (w), 1698 (m), $1625(\mathrm{~m}), 1611(\mathrm{~m}), 1493(\mathrm{w}), 1452$ (w), 1367 (s), 1308 (s), $1018(\mathrm{~m}), 921$ (s), $766(\mathrm{~m}), 755(\mathrm{~m})$, 
745 (s) $\mathrm{cm}^{-1}$. Mass Spec. (EI, +ve mode): exact mass calculated for $\mathrm{C}_{21} \mathrm{H}_{18} \mathrm{~N}_{4} \mathrm{O}_{3}$ : 374.1379 ; exact mass found: 374.1374 ; difference $-1.3 \mathrm{ppm}$.

6-Oxoverdazyl 13. In air, tetrazane $12(1.03 \mathrm{~g}, 2.75 \mathrm{mmol})$ was slurried in toluene/EtOAc $(75 / 25 \mathrm{~mL})$ at $60{ }^{\circ} \mathrm{C}$. Benzoquinone $(0.45 \mathrm{~g}, 4.2 \mathrm{mmol})$ was added, and the resulting yellow mixture was refluxed for $3 \mathrm{~h}$. Upon cooling to room temperature, the resulting red slurry was filtered, and the solid rinsed with toluene and $\mathrm{MeOH}$. Recrystallization from 1:1 THF/EtOAc afforded red fibers. Yield $=0.79$ g, 78\%. M.p.: $>250{ }^{\circ}$ C. FT-IR (ATR): 2893 (br, w), $2676(w)$, $1741(\mathrm{w}), 1695$ (s), $1616(\mathrm{~m}), 1458(\mathrm{w}), 1428(\mathrm{~m}), 1359(\mathrm{~m}), 1311(\mathrm{~m}), 1289(\mathrm{~m}), 1242(\mathrm{~m})$, $1133(\mathrm{~m}), 1119(\mathrm{~m}), 1018(\mathrm{~m}), 898(\mathrm{w}), 866(\mathrm{w}), 778(\mathrm{~m}), 742(\mathrm{~s}) \mathrm{cm}^{-1}$. UV-vis $\left(\mathrm{CH}_{2} \mathrm{Cl}_{2}\right): \lambda_{\max }=$ $546 \mathrm{~nm}\left(\varepsilon=2,150 \mathrm{M}^{-1} \mathrm{~cm}^{-1}\right), 438 \mathrm{~nm}\left(\varepsilon=1,700 \mathrm{M}^{-1} \mathrm{~cm}^{-1}\right), 321 \mathrm{~nm}\left(\varepsilon=11,500 \mathrm{M}^{-1} \mathrm{~cm}^{-1}\right)$, $278 \mathrm{~nm}\left(\varepsilon=25,800 \mathrm{M}^{-1} \mathrm{~cm}^{-1}\right)$. Mass Spec. (EI, +ve mode): exact mass calculated for $\mathrm{C}_{21} \mathrm{H}_{15} \mathrm{~N}_{4} \mathrm{O}_{3}: 371.1144$; exact mass found: 371.1140; difference $-1.1 \mathrm{ppm}$.

6-Oxoverdazyl monomer 15. To a solution of 1-ethyl-3-(3-dimethylaminopropyl)carbodiimide hydrochloride $(\mathrm{EDC} \cdot \mathrm{HCl})(0.33 \mathrm{~g}, 1.7 \mathrm{mmol})$ in dry $\mathrm{CH}_{2} \mathrm{Cl}_{2}(40 \mathrm{~mL})$ and dry $\mathrm{NEt}_{3}(230 \mu \mathrm{L}$, $0.167 \mathrm{~g}, 1.65 \mathrm{mmol}$ ) was added 4-dimethylaminopyridine (DMAP) (0.23 g, $1.9 \mathrm{mmol}$ ) and 6oxoverdazyl $13(0.57 \mathrm{~g}, 1.5 \mathrm{mmol})$ before the mixture was stirred for $20 \mathrm{~min}$ at room temperature. To this slurry was added $N$-(3-hydroxypropyl)-cis-5-norbornene-exo-2,3dicarboximide $14(0.34 \mathrm{~g}, 1.5 \mathrm{mmol})$ dissolved in dry $\mathrm{CH}_{2} \mathrm{Cl}_{2}(10 \mathrm{~mL})$. The reaction was stirred overnight at room temperature. The clear red solution was poured into $1 \mathrm{M} \mathrm{HCl}$. Following stirring for $20 \mathrm{~min}$, the mixture was filtered and rinsed with $\mathrm{CH}_{2} \mathrm{Cl}_{2}$. The organics were extracted into $\mathrm{CH}_{2} \mathrm{Cl}_{2}$, washed with $1 \mathrm{M} \mathrm{HCl}, \mathrm{H}_{2} \mathrm{O}$, saturated $\mathrm{NaHCO}_{3}$ and brine solutions, dried over $\mathrm{MgSO}_{4}$, gravity filtered and concentrated in vacuo. The resulting residue was purified by column chromatography (EtOAc, neutral alumina) followed by recrystallization from $i \mathrm{PrOH}$ to afford the 
title product as a light purple solid. Yield $=0.53$ g, 60\%. M.p.: $136-138^{\circ}$ C. FT-IR (ATR): 2982 (w), $1770(w), 1695$ (s), 1485 (w), 1396 (w), 1358 (w), 1305 (w), $1272(\mathrm{~m}), 1182(\mathrm{w}), 1123(\mathrm{~m})$, $1099(\mathrm{~m}), 744(\mathrm{~m}) \mathrm{cm}^{-1}$. UV-vis $\left(\mathrm{CH}_{2} \mathrm{Cl}_{2}\right): \lambda_{\max }=546 \mathrm{~nm}\left(\varepsilon=2,250 \mathrm{M}^{-1} \mathrm{~cm}^{-1}\right), 436 \mathrm{~nm}(\varepsilon=$ $\left.1,700 \mathrm{M}^{-1} \mathrm{~cm}^{-1}\right), 322 \mathrm{~nm}\left(\varepsilon=12,200 \mathrm{M}^{-1} \mathrm{~cm}^{-1}\right), 278 \mathrm{~nm}\left(\varepsilon=27,300 \mathrm{M}^{-1} \mathrm{~cm}^{-1}\right.$ ). Mass Spec. (EI, +ve mode): exact mass calculated for $\mathrm{C}_{33} \mathrm{H}_{28} \mathrm{~N}_{5} \mathrm{O}_{5}{ }^{\circ}:$ 574.2090; exact mass found: 574.2103; difference +2.3 ppm. Anal. Calcd. (\%) for $\mathrm{C}_{33} \mathrm{H}_{28} \mathrm{~N}_{5} \mathrm{O}_{5}$ : C, 68.98; H, 4.91; N, 12.19. Found: C, $68.59 ; \mathrm{H}, 4.62 ; \mathrm{N}, 12.19$.

6-Oxoverdazyl Polymer 16. A grease-free Schlenk flask was charged with monomer 15 (0.21 g, $0.37 \mathrm{mmol})$ and dry $\mathrm{CH}_{2} \mathrm{Cl}_{2}(14 \mathrm{~mL})$. The resulting red solution was degassed by three freezepump-thaw cycles. The monomer solution was then cooled to $0{ }^{\circ} \mathrm{C}$ in an ice bath for $10 \min$ before a similarly degassed $1.3 \mathrm{mg} \mathrm{mL}^{-1} \mathrm{CH}_{2} \mathrm{Cl}_{2}$ solution of Grubbs' $3^{\text {rd }}$ generation catalyst (2.5 $\mathrm{mL}, 3.7 \times 10^{-3} \mathrm{mmol}$ ) was rapidly added in one portion. The polymerization proceeded for $1 \mathrm{~h}$ before it was terminated with ethyl vinyl ether $(0.70 \mathrm{~mL}, 0.53 \mathrm{~g}, 7.3 \mathrm{mmol})$, and stirred for an additional 30 min while warming to room temperature. The crude mixture was filtered through a short neutral alumina plug before the solvent was removed in vacuo. The resultant polymer, a red oil, was dissolved in minimal THF and precipitated twice into rapidly stirred cold pentane (60 $\mathrm{mL}$ ) to afford the title product as a red powder upon drying under vacuum. Yield $=0.18 \mathrm{~g}, 85 \%$. FT-IR (ATR): 2951 (w), 1772 (w), 1701 (s), 1696 (s), 1484 (m), 1398 (m), 1358 (m), 1271 (m), $1241(\mathrm{~m}), 1177$ (m), $1123(\mathrm{~m}), 1100(\mathrm{~m}), 1018(\mathrm{~m}), 866(\mathrm{~m}), 752(\mathrm{~m}) \mathrm{cm}^{-1}$. UV-vis $\left(\mathrm{CH}_{2} \mathrm{Cl}_{2}\right)$ : $\lambda_{\max }=548 \mathrm{~nm}\left(\varepsilon=2,200 \mathrm{M}^{-1} \mathrm{~cm}^{-1}\right), 439 \mathrm{~nm}\left(\varepsilon=1,650 \mathrm{M}^{-1} \mathrm{~cm}^{-1}\right), 322 \mathrm{~nm}(\varepsilon=$ $\left.11,400 \mathrm{M}^{-1} \mathrm{~cm}^{-1}\right), 278 \mathrm{~nm}\left(\varepsilon=25,600 \mathrm{M}^{-1} \mathrm{~cm}^{-1}\right)$. GPC (THF, conventional calibration relative to polystyrene standards): $\mathrm{M}_{\mathrm{n}}=42,000 \mathrm{~g} \mathrm{~mol}^{-1}, \mathrm{M}_{\mathrm{w}}=46,600 \mathrm{~g} \mathrm{~mol}^{-1}, Ð=1.11$ ). 


\section{Dihydroxyimidazolidine 18.}

This procedure was adapted from a version published by Miller and co-workers. ${ }^{24}$ To a solution of 2,3-bis(hydroxyamino)-2,3-dimethylbutane $17(0.37 \mathrm{~g}, 2.5 \mathrm{mmol})$ in $\mathrm{MeOH}(10 \mathrm{~mL})$ was added 4-carboxybenzaldehyde $(0.31 \mathrm{~g}, 2.1 \mathrm{mmol})$ in air. The mixture was then stirred at room temperature for $48 \mathrm{~h}$. The resulting white precipitate was isolated via vacuum filtration, washed with cold $\mathrm{MeOH}$, and then dried in vacuo to give 18 as a white solid. Yield $=0.46$ g, $79 \%$. M.p.: $>184{ }^{\circ} \mathrm{C}$ (decomp.). ${ }^{1} \mathrm{H}$ NMR (400.1 MHZ, DMSO-d $\left.d_{6}\right): \delta 12.83$ (s, 1H, COOH), 7.92 (d, 2H, ${ }^{3} J_{\mathrm{HH}}=8 \mathrm{~Hz}$, aryl $\left.\mathrm{CH}\right), 7.84(\mathrm{~s}, 2 \mathrm{H}, \mathrm{OH}), 7.60\left(\mathrm{~d}, 2 \mathrm{H},{ }^{3} J_{\mathrm{HH}}=8 \mathrm{~Hz}\right.$, aryl CH), $4.58(\mathrm{~s}, 1 \mathrm{H}, \mathrm{CH})$, $1.09(\mathrm{~s}, 6 \mathrm{H}, \mathrm{CH}), 1.05\left(\mathrm{~s}, 6 \mathrm{H}, \mathrm{CH}_{3}\right) .{ }^{13} \mathrm{C}\left\{{ }^{1} \mathrm{H}\right\}$ NMR (150.7 MHz, DMSO- $\left.d_{6}\right): \delta 167.8,147.5$, 130.2, 129.2, 128.9, 90.3, 66.8, 24.8, 17.7. FT-IR (ATR): 3248 (m), 2995 (w), 1611 (w), 1558 (w), 1436 (s), 1366 (m), 1294 (w), 1215 (w), 769 (w), 705 (w). $\mathrm{cm}^{-1}$. Mass Spec. (EI, +ve mode): exact mass calculated for $\mathrm{C}_{14} \mathrm{H}_{20} \mathrm{~N}_{2} \mathrm{O}_{4}$ : 280.1423; found: 280.1418; difference: $-1.8 \mathrm{ppm}$.

\section{Nitronyl Nitroxide 19.}

This procedure was adapted from a version published by Miller and co-workers. ${ }^{24}$ To a suspension of 2-(4'-carboxyphenyl)-4,4,5,5-tetramethyl-1,3-dihydroxyimidazolidine 18 (0.43 g, $1.5 \mathrm{mmol})$ in THF $(15 \mathrm{~mL})$ and $1 \mathrm{M} \mathrm{NaOH}(1.5 \mathrm{~mL}, 1.5 \mathrm{mmol})$ was added dropwise a solution of sodium periodate $(0.49 \mathrm{~g}, 2.3 \mathrm{mmol})$ in $\mathrm{H}_{2} \mathrm{O}(15 \mathrm{~mL})$ over a $15 \mathrm{~min}$ period. The reaction mixture was then stirred at room temperature for $1 \mathrm{~h}$ open to air before the organics were combined with EtOAc $(30 \mathrm{~mL})$ and $\mathrm{HCl}(3 \mathrm{~mL}, 1 \mathrm{M})$. The mixture was subsequently washed with $\mathrm{H}_{2} \mathrm{O}(3 \times 30 \mathrm{~mL})$ and brine $(3 \times 40 \mathrm{~mL})$. The organic layer was separated, dried with $\mathrm{MgSO}_{4}$, and taken to dryness in vacuo yielding 19 as a dark blue microcrystalline solid. Yield = 0.27 g, 65\%. M.p.: >196 ${ }^{\circ} \mathrm{C}$ (decomp.) FT-IR (ATR): 2922 (br, m), 2498 (br, m), 1700 (s), 1340 (s), $1257(\mathrm{~s}), 1108(\mathrm{w}), 1018(\mathrm{~m}), 855(\mathrm{w}) \mathrm{cm}^{-1}$. UV-vis $\left(\mathrm{CH}_{2} \mathrm{Cl}_{2}\right): \lambda_{\max }=645 \mathrm{~nm}\left(\varepsilon=200 \mathrm{M}^{-1}\right.$ 
$\left.\mathrm{cm}^{-1}\right), 602 \mathrm{~nm}\left(\varepsilon=240 \mathrm{M}^{-1} \mathrm{~cm}^{-1}\right), 563 \mathrm{~nm}\left(\varepsilon=200 \mathrm{M}^{-1} \mathrm{~cm}^{-1}\right), 380 \mathrm{~nm}\left(\varepsilon=9,300 \mathrm{M}^{-1} \mathrm{~cm}^{-1}\right)$, $365 \mathrm{~nm}\left(\varepsilon=4,900 \mathrm{M}^{-1} \mathrm{~cm}^{-1}\right), 295 \mathrm{~nm}\left(\varepsilon=11,500 \mathrm{M}^{-1} \mathrm{~cm}^{-1}\right)$. Mass Spec. (EI, +ve mode): exact mass calculated for $\mathrm{C}_{14} \mathrm{H}_{17} \mathrm{~N}_{2} \mathrm{O}_{4}$ : 277.1188; found: 277.1191; difference: $+1.1 \mathrm{ppm}$.

\section{Nitronyl Nitroxide Monomer 20.}

To a solution of $N, N^{\prime}$-dicyclohexylcarbodiimide (DCC) $(0.31 \mathrm{~g}, 1.5 \mathrm{mmol})$ and DMAP $(0.20 \mathrm{~g}$, $1.6 \mathrm{mmol})$ in dry $\mathrm{CH}_{2} \mathrm{Cl}_{2}(10 \mathrm{~mL})$ was added nitronyl nitroxide $\mathbf{1 9}(0.38 \mathrm{~g}, 1.4 \mathrm{mmol})$ before the mixture was stirred for $10 \mathrm{~min}$ at room temperature. To this solution was added $\mathrm{N}$-[3hydroxylpropyl]-cis-5-norbornene-exo-2,3-dicarboximide $14(0.33 \mathrm{~g}, 1.5 \mathrm{mmol})$ in dry $\mathrm{CH}_{2} \mathrm{Cl}_{2}$ ( $3 \mathrm{~mL})$. The reaction mixture was then stirred for $18 \mathrm{~h}$ before it was filtered to remove a white precipitate. The resulting dark blue solution was then taken to dryness in vacuo. The resulting dark blue oil was purified by column chromatography [neutral alumina, hexanes/EtOAc (2:1)], and recrystallized from a hot saturated solution of $i \mathrm{PrOH}$ to give monomer $\mathbf{2 0}$ as a blue powder. Yield $=0.41$ g, 63\%. M.p.: 146-148 ${ }^{\circ}$ C. FT-IR (ATR): 2960 (br, m), 1774 (m), 1719(s), 1697 (w), $1430(\mathrm{~m}), 1390(\mathrm{~s}), 1360$ (s), 1272 (s), 1177, (m), $1122(\mathrm{~m}) \mathrm{cm}^{-1}$. UV-vis $\left(\mathrm{CH}_{2} \mathrm{Cl}_{2}\right): \lambda_{\max }=$ $645 \mathrm{~nm}\left(\varepsilon=240 \mathrm{M}^{-1} \mathrm{~cm}^{-1}\right), 602 \mathrm{~nm}\left(\varepsilon=300 \mathrm{M}^{-1} \mathrm{~cm}^{-1}\right), 563 \mathrm{~nm}\left(\varepsilon=240 \mathrm{M}^{-1} \mathrm{~cm}^{-1}\right), 380 \mathrm{~nm}(\varepsilon$ $\left.=11,300 \mathrm{M}^{-1} \mathrm{~cm}^{-1}\right), 365 \mathrm{~nm}\left(\varepsilon=6,000 \mathrm{M}^{-1} \mathrm{~cm}^{-1}\right), 295 \mathrm{~nm}\left(\varepsilon=14,000 \mathrm{M}^{-1} \mathrm{~cm}^{-1}\right)$. Mass Spec. (EI, +ve mode): exact mass calculated for $\mathrm{C}_{26} \mathrm{H}_{30} \mathrm{~N}_{3} \mathrm{O}_{6}$ : 480.2135; found: 480.2138; difference: +0.8 ppm. Anal. Calcd. (\%) for $\mathrm{C}_{26} \mathrm{H}_{30} \mathrm{~N}_{3} \mathrm{O}_{6}$ : C, 64.99; H, 6.29; N, 8.74. Found: C, 64.92; H, $6.16 ; \mathrm{N}, 8.72$.

\section{Nitronyl Nitroxide Polymer 21.}

A grease-free Schlenk flask was charged with monomer $20(0.10 \mathrm{~g}, 0.21 \mathrm{mmol})$ and dry $\mathrm{CH}_{2} \mathrm{Cl}_{2}$ (3.0 mL). The resulting blue solution was degassed by by three freeze-pump-thaw cycles. The monomer solution was then cooled to $0{ }^{\circ} \mathrm{C}$ in an ice bath for $5 \mathrm{~min}$ before a $1 \mathrm{mg} \mathrm{mL} \mathrm{mL}^{-1} \mathrm{CH}_{2} \mathrm{Cl}_{2}$ 
solution of Grubbs' $3^{\text {rd }}$ generation catalyst $\left(1.84 \mathrm{~mL}, 2.1 \times 10^{-3} \mathrm{mmol}\right)$ was quickly added. The polymerization proceeded for 30 min before it was terminated with ethyl vinyl ether $(0.40 \mathrm{~mL}$, $0.30 \mathrm{~g}, 4.2 \mathrm{mmol}$ ) and the mixture was stirred for an additional $30 \mathrm{~min}$ at room temperature. The crude reaction mixture was filtered through a short neutral alumina plug and the solvent was removed in vacuo. The resulting polymer was dissolved in minimal THF and precipitated into rapidly stirred cold pentane $(40 \mathrm{~mL})$ thrice to afford 21 as a blue powder. Yield $=0.086 \mathrm{~g}, 86 \%$. FT-IR (ATR): 2950 (m), 1774 (w), 1697 (s), 1447 (m), 1394 (s), 1360 (s), 1268 (s), 1174, (m), $1113(\mathrm{~m}) \mathrm{cm}^{-1}$. UV-vis $\left(\mathrm{CH}_{2} \mathrm{Cl}_{2}\right): \lambda_{\max }=645 \mathrm{~nm}\left(\varepsilon=230 \mathrm{M}^{-1} \mathrm{~cm}^{-1}\right), 602 \mathrm{~nm}(\varepsilon=$ $\left.280 \mathrm{M}^{-1} \mathrm{~cm}^{-1}\right), 563 \mathrm{~nm}\left(\varepsilon=230 \mathrm{M}^{-1} \mathrm{~cm}^{-1}\right), 380 \mathrm{~nm}\left(\varepsilon=10,400 \mathrm{M}^{-1} \mathrm{~cm}^{-1}\right), 365 \mathrm{~nm}(\varepsilon=5,600$ $\left.\mathrm{M}^{-1} \mathrm{~cm}^{-1}\right), 295 \mathrm{~nm}\left(\varepsilon=13,000 \mathrm{M}^{-1} \mathrm{~cm}^{-1}\right)$. GPC (THF, conventional calibration relative to polystyrene standards): $\mathrm{M}_{\mathrm{n}}=51,400 \mathrm{~g} \mathrm{~mol}^{-1}, \mathrm{M}_{\mathrm{w}}=60,600 \mathrm{~g} \mathrm{~mol}^{-1}, Ð=1.18$.

\section{Catalyst Loading Study}

Five separate reactions were carried out each using $0.05 \mathrm{~g}(0.10 \mathrm{mmol})$ of nitronyl nitroxide monomer 20. The polymerization procedure was as listed above. Catalyst molar feed stock ratios (monomer:catalyst) varied from 20, 40, 60, 80 and 100. All reaction times were 30 min. Each polymer sample was run through a short neutral alumina plug, dried in vacuo, re-dissolved in GPC-grade THF and then analyzed by GPC.

\section{Reaction Progress as a Function of Time}

A $4.6 \mathrm{mg} \mathrm{mL}^{-1} \mathrm{CH}_{2} \mathrm{Cl}_{2}$ solution of Grubbs' $3^{\text {rd }}$ generation catalyst $\left(1.0 \mathrm{~mL}, 5.2 \times 10^{-3} \mathrm{mmol}\right)$ was added rapidly to a $50 \mathrm{mg} \mathrm{mL} \mathrm{CH}_{2} \mathrm{Cl}_{2}$ stirring solution of monomer 20 (5.0 mL, 0.52 mmol). The mixture was stirred on ice for $1 \mathrm{~h}$. Five different timed aliquots $(1 \mathrm{~mL})$ were acquired over the span of the reaction time, with each one transferred to a greaseless Schlenk flask containing ethyl vinyl ether $(0.15 \mathrm{~mL}, 1.5 \mathrm{mmol})$. Following termination, each polymer 
was run through a short neutral alumina plug, dried in vacuo, re-dissolved in GPC-grade THF and then analyzed by GPC.

\section{RESULTS AND DISCUSSION}

\section{Synthesis}

The synthetic pathways used for the production of the target polymers in this study are shown in

Scheme 1. A condensation reaction between 2,4-diphenylcarbonohydrazide $\mathbf{1 1}^{19}$ and 4carboxybenzaldehyde produced tetrazane $\mathbf{1 2}$ in $98 \%$ yield (Figures S1 and S2). The tetrazane was converted to 6-oxoverdazyl 13 in $78 \%$ yield using benzoquinone as an oxidant in refluxing toluene. Esterification to produce monomer 15 was accomplished via an EDC coupling reaction between radical 13 and $N$-[3-hydroxylpropyl]-cis-5-norbornene-exo-2,3-dicarboximide 14 in $60 \%$ yield. We chose to oxidize the tetrazane to the 6-oxoverdazyl prior to esterification as our oxidation conditions resulted in ester cleavage when the reaction order was reversed. In a typical ROMP reaction, 1 mol\% of Grubbs III was combined with a degassed $\mathrm{CH}_{2} \mathrm{Cl}_{2}$ solution of monomer 15 and allowed to react at $0{ }^{\circ} \mathrm{C}$ for $1 \mathrm{~h}$. Subsequent termination with ethyl vinyl ether, catalyst removal, and purification via precipitation from THF into rapidly stirred cold pentane afforded polymer $16\left(\mathrm{M}_{\mathrm{n}}=42,000 \mathrm{~g} \mathrm{~mol}^{-1}, \mathrm{M}_{\mathrm{w}}=46,600 \mathrm{~g} \mathrm{~mol}^{-1}, Ð=1.11 ;\right.$ Figure $\left.\mathrm{S} 3\right)$ in $85 \%$ yield.

Similarly, the reaction between 2,3-bis(hydroxyamino)-2,3-dimethylbutane $\mathbf{1 7}^{21}$ and 4carboxybenzaldehyde afforded dihydroxyimidazolidine $\mathbf{1 8}$ in 79\% yield (Figures S4 and S5). Treatment of 18 with $\mathrm{NaIO}_{4}$ produced nitronyl nitroxide radical 19 (65\%), which was subsequently combined with $\mathbf{1 4}$ in a DCC coupling reaction to produce monomer $\mathbf{2 0}$ in $63 \%$ yield. Polymerization as described above gave polymer $21\left(\mathrm{M}_{\mathrm{n}}=51,400 \mathrm{~g} \mathrm{~mol}^{-1}, \mathrm{M}_{\mathrm{w}}=60,600 \mathrm{~g}\right.$ 
$\mathrm{mol}^{-1}, Ð=1.18$; Figure S3) in $86 \%$ yield. The polymer samples described above were used to generate the characterization data discussed in the subsequent sections.

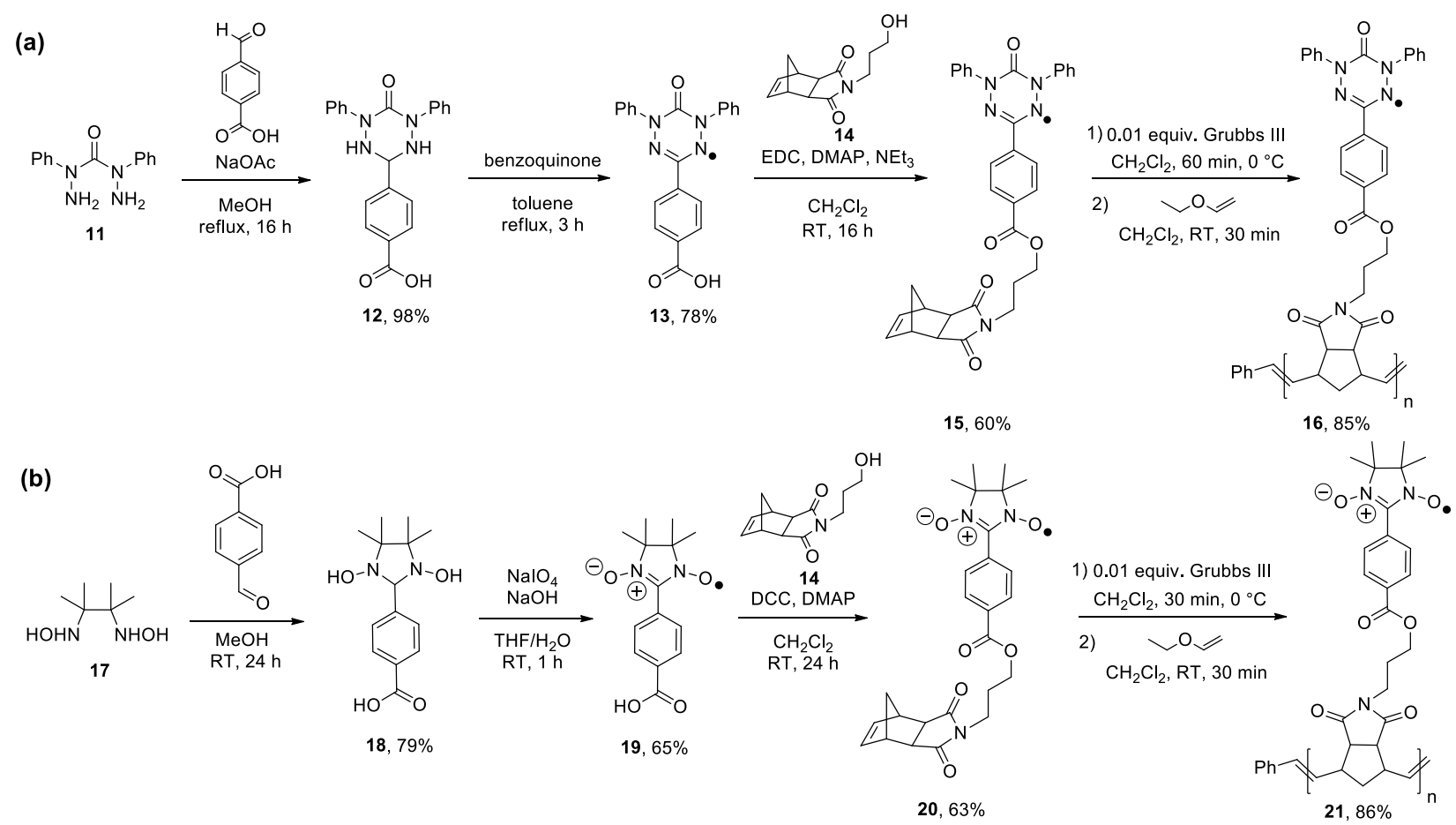

Scheme 1. Synthesis of (a) 6-oxoverdazyl monomer 15 and polymer 16 and (b) nitronyl nitroxide monomer 20 and polymer 21.

We have previously shown that similar ROMP reactions are compatible with 6oxoverdazyl monomers. ${ }^{16 \mathrm{~b}}$ Because of the narrow MW distributions (see above) and high radical content (see below) established for polymer 16, we did not reinvestigate the ROMP reaction for this class of radical monomers in detail. Given the propensity of nitronyl nitroxides to form iminonitroxides via oxygen abstraction, ${ }^{25}$ and the potential reactivity associated with radicals, we endeavored to explore the ROMP of monomer $\mathbf{2 0}$ in detail (Figure 1). The scope of the studies we could perform were limited by the paramagnetic nature of the monomer/polymer involved, which prevented us from using NMR spectroscopy as an analysis tool. First, reaction progress was monitored as a function of time (monomer:catalyst ratio 100:1) revealing that the rate of 
molecular weight increase was largest in the early stages of the reaction when monomer concentration was maximal (Figure 1a). The molecular weight began to plateau after approximately $20 \mathrm{~min}$, reaching a maximum $\mathrm{M}_{\mathrm{n}}$ of 45,000 $\mathrm{g} \mathrm{mol}^{-1}$ after $60 \mathrm{~min}$. The molecular weight distributions for the aliquots of polymer removed at the various time intervals were very narrow, with dispersities $(\bigoplus)$ ranging from 1.05 in the early stages of the reaction to 1.13 after 60 min. These values were significantly lower than those obtained for the ROMP of a related nitronyl-nitroxide-containing monomer ${ }^{15 \mathrm{f}}$ and similar to those obtained for polymers based on nitroxide radicals. $^{26}$

A second study allowed for the polymerization to be studied as a function of feed molar ratio (i.e., monomer:catalyst ratio) (Figure 1b/c). The GPC data collected for the polymers produced at various feed molar ratios were indicative of narrow molecular weight distributions $(\bigoplus=1.09-1.26)$ and revealed a linear relationship $\left(\mathrm{R}^{2}=0.99\right)$ between the number average degree of polymerization $\left(\mathrm{DP}_{\mathrm{n}}\right)$ and feed molar ratio. We believe that the low molecular weight tailing in the GPC traces is indicative of significant polymer-column interactions arising due to the presence of the polar N-O functional groups. Furthermore, the deviation from ideal behavior (black line, Figure 1b) indicates that our GPC analysis using conventional calibration relative to polystyrene standards systematically overestimates the molecular weights of samples of polymer 21. Taken together, these studies indicate that the ROMP of monomer $\mathbf{2 0}$ to produce polymer $\mathbf{2 1}$ exhibits characteristics of a living polymerization and provides predictable and reproducible control of molecular weight and narrow molecular weight distributions. 

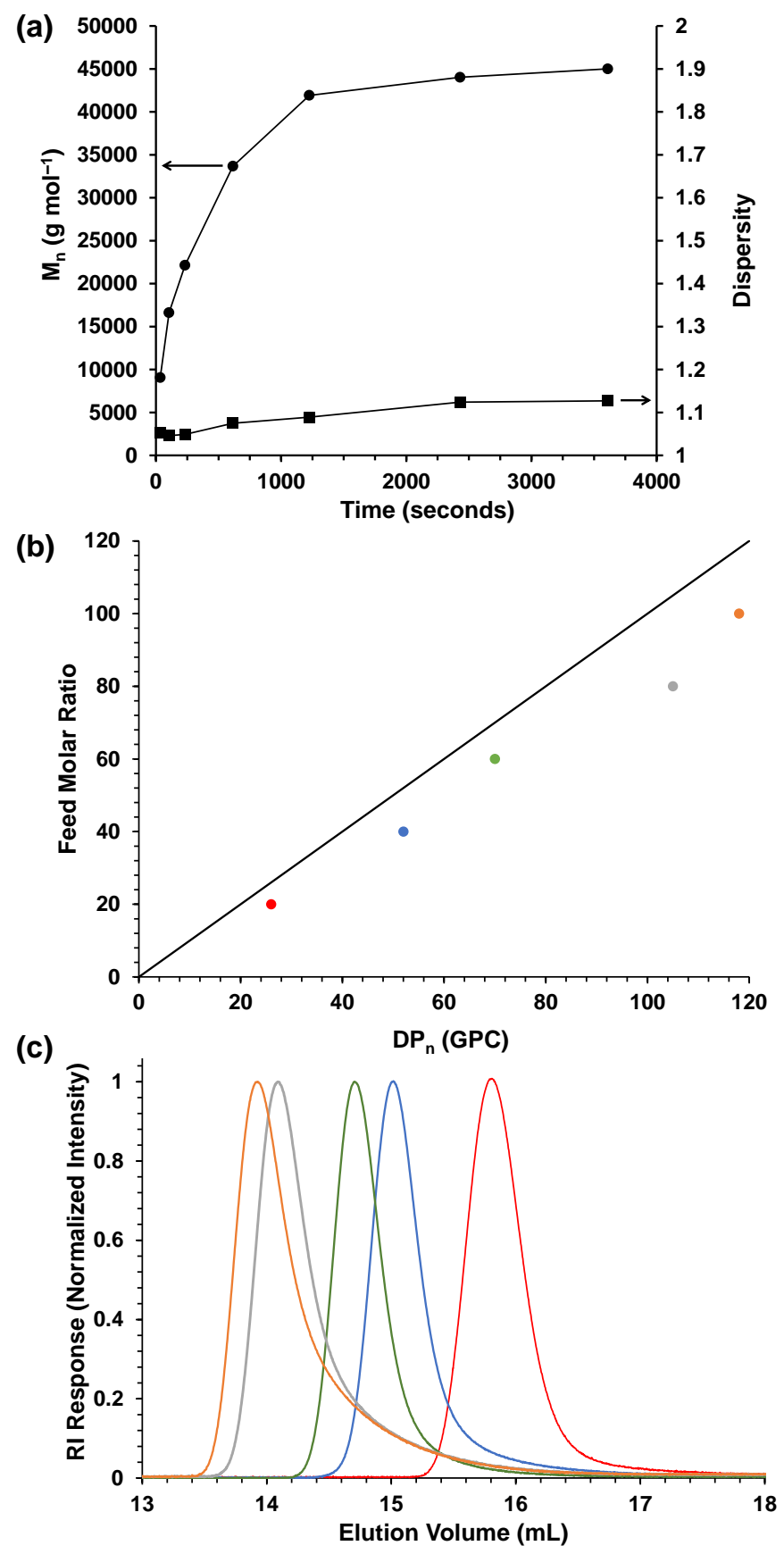

Figure 1. (a) Molecular weight of nitronyl nitroxide polymer 21 as a function of polymerization time. (b) Relationship of feed molar ratio and $\mathrm{DP}_{\mathrm{n}}(\mathrm{GPC})$ for nitronyl nitroxide polymer $\mathbf{2 1}$. The black line represents the idealized relationship. (c) GPC traces for various samples of nitronyl nitroxide polymer 21 corresponding to the data presented in panel (b). 


\section{FT-IR, UV-vis Absorption, and EPR Spectroscopy}

The primary and electronic structures of polymers $\mathbf{1 6}$ and $\mathbf{2 1}$ and their respective monomer building blocks were examined using FT-IR, UV-vis absorption, and electron paramagnetic resonance (EPR) spectroscopy (Figures 2 and S6). The IR spectra collected for the 6oxoverdazyl monomer/polymer $\left[v(\mathrm{CO})=1695 \mathrm{~cm}^{-1}\right]$ and nitronyl nitroxide monomer/polymer $\left[v(\mathrm{CO})=1697 \mathrm{~cm}^{-1} ; v(\mathrm{NO}) \sim 1360 \mathrm{~cm}^{-1}\right]$ were qualitatively very similar with slight broadening observed in the spectra of the polymers collected for each family of compounds, indicating that the ROMP reactions employed did not result in decomposition of the pendant radical units. Similarly, the UV-vis spectra for the respective pairs of monomers and polymers were wellmatched with lower energy absorption maxima $\left(\lambda_{\max }\right)$ at $c a .550 \mathrm{~nm}$ for the 6-oxoverdazyls and ca. $600 \mathrm{~nm}$ for the nitronyl nitroxides. The EPR spectrum of monomer $15(g=2.0038)$ contained fine structure consistent with hyperfine coupling to two pairs of equivalent nitrogen atoms $\left(a_{\mathrm{N} 1,5}\right.$ $=0.460 \mathrm{mT} ; a_{\mathrm{N} 2,4}=0.647 \mathrm{mT}$ ), consistent with the electronic structure revealed for related systems using X-Ray absorption near-edge structure (XANES) spectroscopy. ${ }^{27}$ This fine structure was lost in the spectrum of polymer $16(g=2.0039)$ due to the close proximity of the radical units within the polymer backbone. The spectrum collected for monomer $\mathbf{2 0}(g=2.0060)$ exhibited a five line pattern due to coupling to two equivalent nitrogen atoms $\left(a_{\mathrm{N}}=0.754 \mathrm{mT}\right)$, which similarly disappeared in the spectrum of polymer $21(g=2.0070)$. These qualitative data are consistent with those of other 6-oxoverdazyls ${ }^{16 a, 28}$ and nitronyl nitroxides. ${ }^{15 c}$

Quantitative analysis of the number of repeating units containing radicals for polymers 16 and 21 was conducted using UV-vis absorption and EPR spectroscopy. Comparison of the intensities of the UV-vis absorption at the low-energy $\lambda_{\max }$ allowed us to estimate that 96 and 97\% of the repeating units in polymers $\mathbf{1 6}$ and $\mathbf{2 1}$ contained 6-oxoverdazyl and nitronyl nitroxide 
radicals, respectively. By comparing the integration of EPR spectra generated for solid samples of polymer 16 and 21 and samples of TEMPO with similar sample shape, mass, and volume, estimates of the radical content of 98 and $97 \%$ were obtained. Collectively, these data support our conclusions that the ROMP reactions employed are tolerant of 6-oxoverdazyl and nitronyl nitroxide radicals and that the polymer samples produced have very high radical content.
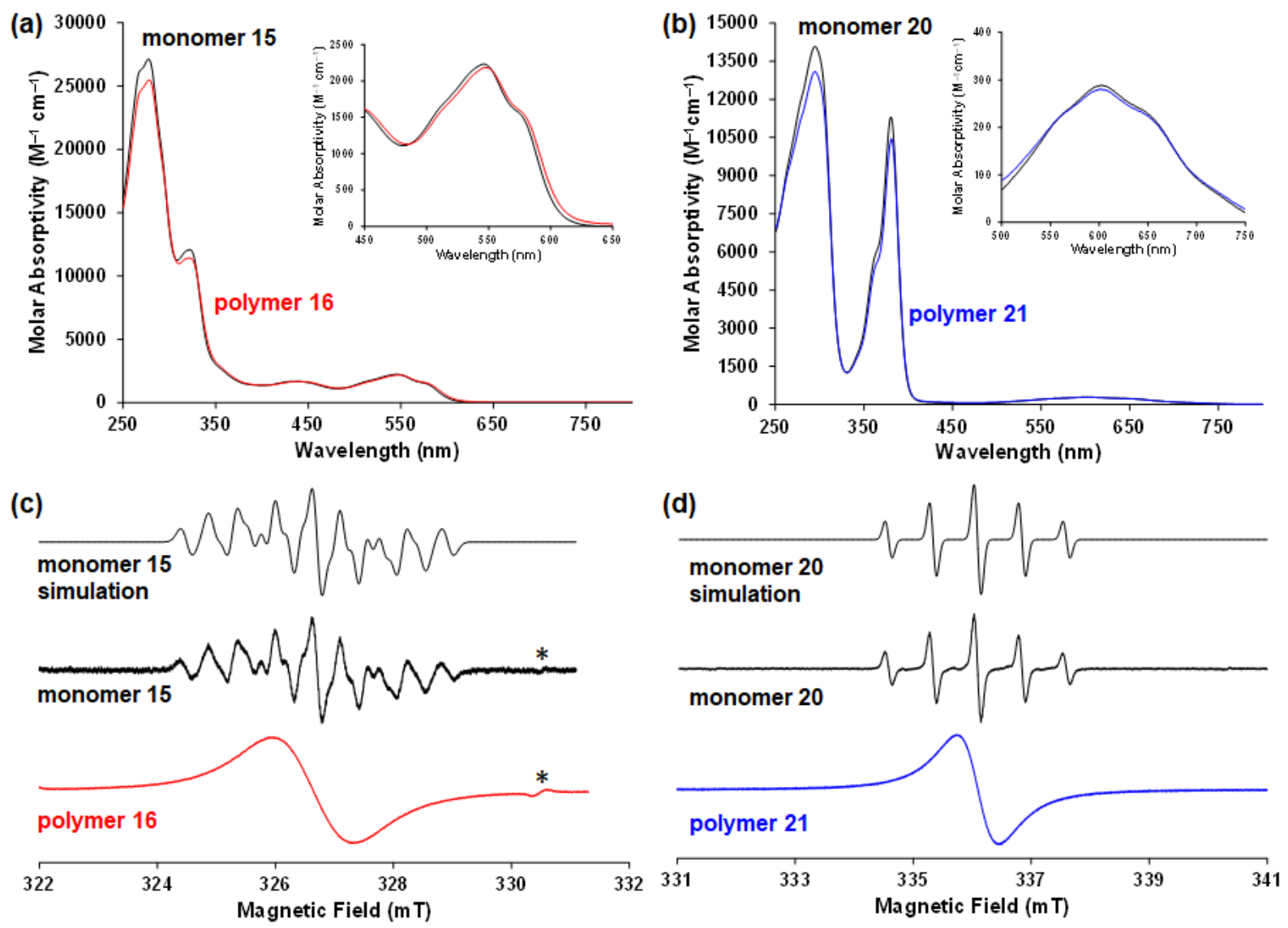

Figure 2. UV-vis absorption spectra of (a) 6-oxoverdazyl monomer $\mathbf{1 5}$ and polymer $\mathbf{1 6}$ and (b) nitronyl nitroxide monomer 20 and polymer 21. The insets show magnifications of the characteristic transitions for each radical type. Simulated and experimental EPR spectra for (c) 6oxoverdazyl monomer $15(g=2.0038)$ and polymer $16(g=2.0039)$ and $(d)$ nitronyl nitroxide monomer $20(g=2.0060)$ and polymer $21(g=2.0070)$. The simulations yielded the following parameters for 15: $a_{\mathrm{N} 1,5}=0.460 \mathrm{mT} ; a_{\mathrm{N} 2,4}=0.647 \mathrm{mT}$; line width $=0.20 \mathrm{mT}$ and 20: $a_{\mathrm{N}}=$ $0.754 \mathrm{mT}$, line width $=0.12 \mathrm{mT}$. The asterisks denote signals arising from the built-in $\mathrm{Mn}^{2+}$ marker in the resonant cavity of the EPR spectrometer. 


\section{Thermal Analysis}

Thermal gravimetric analysis (TGA) and differential scanning calorimetry (DSC) data collected for polymers $\mathbf{1 6}$ and $\mathbf{2 1}$ are presented in Figures 3 and S7. The TGA trace obtained for 6oxoverdazyl polymer 16 showed an onset of decomposition at $\mathrm{ca} .200{ }^{\circ} \mathrm{C}$, followed by mass loss in three steps to $0 \%$ mass at $850{ }^{\circ} \mathrm{C}$. DSC revealed a glass transition temperature $\left(\mathrm{T}_{\mathrm{g}}\right)$ of $159{ }^{\circ} \mathrm{C}$ for polymer 16, consistent with that previously observed for polymer $\mathbf{1 0}\left(\mathrm{T}_{\mathrm{g}}=152{ }^{\circ} \mathrm{C}\right) .{ }^{16 \mathrm{~b}} \mathrm{The}$ TGA data collected for polymer 21 revealed a similar three-step decomposition signature, and an additional feature between 160 and $190{ }^{\circ} \mathrm{C}$ corresponding to a mass loss of approximately $3 \%$. This mass loss corresponds roughly to one oxygen atom $(3.3 \%)$ in the structure of $\mathbf{2 1}$, indicating that $\mathrm{N}-\mathrm{O}$ bond cleavage is the likely pathway for initial decomposition. Heating a sample of $\mathbf{2 1}$ under $\mathrm{N}_{2}$ at $170{ }^{\circ} \mathrm{C}$ resulted in conversion of the blue solid polymer to a sticky brown residue. FT-IR spectroscopy showed the residue to have a significantly diminished N-O stretch at 1360 $\mathrm{cm}^{-1}$ (Figure S8), corroborating our hypothesis that this initial decomposition occurs via N-O cleavage. DSC studies of polymer 21 up to temperatures of $150{ }^{\circ} \mathrm{C}$ did not reveal a $\mathrm{T}_{\mathrm{g}}$, likely due to the fact that its thermal decomposition preceded the glass transition. 


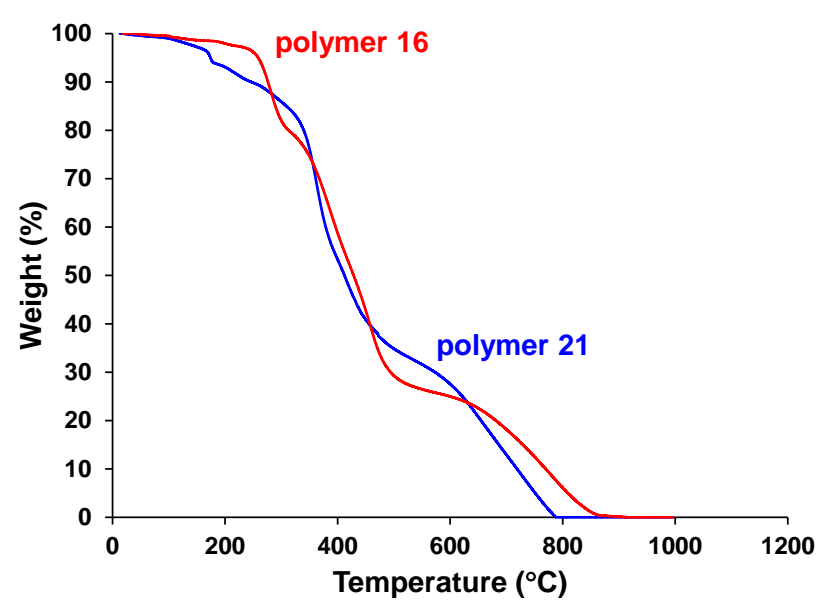

Figure 3. TGA data collected for polymers 6-oxoverdazyl polymer $\mathbf{1 6}$ and nitronyl nitroxide polymer 21 under an atmosphere of $\mathrm{N}_{2}$.

\section{Cyclic Voltammetry}

The electrochemical properties of the radical monomers and polymers described in this study in 50:50 v/v mixtures of $\mathrm{CH}_{3} \mathrm{CN}$ and $\mathrm{CH}_{2} \mathrm{Cl}_{2}$ are presented in Figure 4 and summarized in Table 1. This solvent mixture was employed in an effort to maximize the solubility of the three different redox states of the monomers and polymers that were analyzed. Cyclic voltammetry studies revealed that radical monomers $\mathbf{1 5}$ and $\mathbf{2 0}$ were reversibly oxidized by one electron to their cationic forms $\left(15: E_{1 / 2, \mathrm{ox}}=0.50 \mathrm{~V} ; \mathbf{2 0}: E_{1 / 2, \mathrm{ox}}=0.42 \mathrm{~V}\right.$ relative to the ferrocene/ferrocenium redox couple) and reduced by one electron to their anionic forms $\left(\mathbf{1 5}: E_{1 / 2, \text { red }}=-0.99 \mathrm{~V} ; \mathbf{2 0}\right.$ : $E_{1 / 2 \text {,red }}=-1.27 \mathrm{~V}$ ) demonstrating their ambipolar character. In the case of 6-oxoverdazyl polymer $\mathbf{1 6}$ the voltammogram collected was qualitatively similar to that of monomer $\mathbf{1 5}\left(E_{1 / 2, \mathrm{ox}}=0.49 \mathrm{~V}\right.$; $\left.E_{1 / 2 \text {,red }}=-0.96 \mathrm{~V}\right)$. However, both the diminished current response and peak shapes observed were indicative of a loss of diffusion control associated with the poor mobility and/or poor solubility of the charged/neutral forms of the polymer at the working electrode surface. The cell potential $\left(E_{\text {cell }}\right)$ of $1.45 \mathrm{~V}$ volts was lower than that observed for the related 6-oxoverdazyl 
polymer $10(1.60 \mathrm{~V})$. The voltammogram collected for nitronyl nitroxide polymer 21 was somewhat more intriguing, and to the best of our knowledge represents the first study of the electrochemical properties of a nitronyl nitroxide polymer in solution. The oxidation potential of $0.44 \mathrm{~V}$ is comparable to that of monomer $\mathbf{2 0}$ and the current response and peak shape are once again indicative of the poor mobility and/or solubility at the working electrode interface. However, we were repeatedly unable to observe the reversible reduction of polymer $\mathbf{2 1}$ even when polymer batches, solvents, scan rates (Figure S9), scan direction (Figure S10), and working electrode materials were varied. Others have postulated that the irreversibility of the reduction wave observed for composite electrodes of nitronyl nitroxide polymers is attributed to the formation of hydroxylamines upon protonation of the electrochemically-generated anion. ${ }^{15 \mathrm{~d}} \mathrm{We}$ cannot rule out the possibility that rapid protonation occurs upon reduction due the presence of protic functional groups generated by ester hydrolysis, although we have been unable to observe such hydrolysis products experimentally. Thus, at this stage, we do not have a definitive explanation for our inability to observe a reduction wave for $\mathbf{2 1}$, but we believe that it is reasonable to conclude that electrode fouling due to plating of the electrogenerated anionic/cationic forms of $\mathbf{2 1}$ (Figure S11) or protonation of the reduced form of polymer $\mathbf{2 1}$ may be the cause(s). Regardless, the redox properties of polymers 16 and 21 render them good candidates for use as thin films with potential application in organic electronics. 


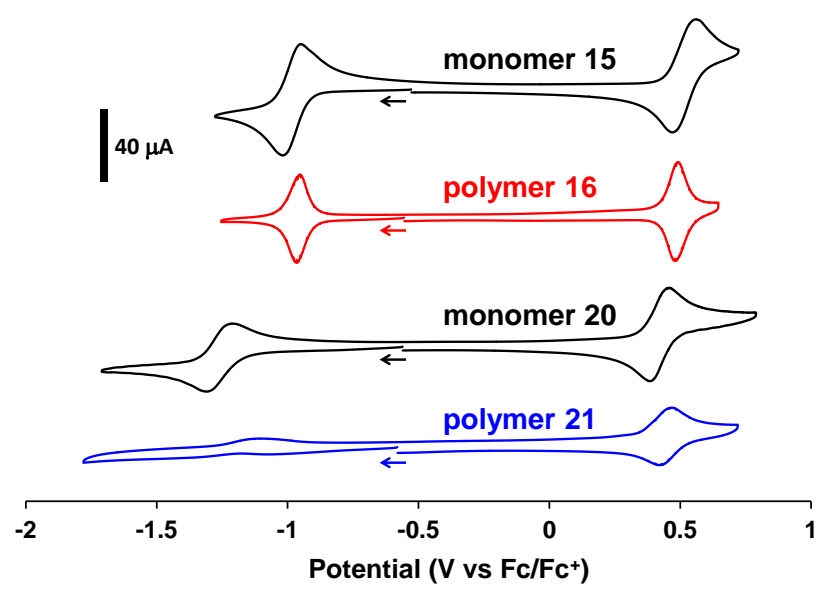

Figure 4. Cyclic voltammograms collected for 6-oxoverdazyl monomer 15 and polymer 16 and nitronyl nitroxide monomer 20 and polymer 21. Experiments were conducted in degassed mixtures of 50:50 v/v $\mathrm{CH}_{2} \mathrm{Cl}_{2} / \mathrm{CH}_{3} \mathrm{CN}$ containing approximately $1 \mathrm{mM}$ of monomer or polymer analyte and $0.1 \mathrm{M}\left[n \mathrm{Bu}_{4} \mathrm{~N}\right]\left[\mathrm{PF}_{6}\right]$ at scan rates of $250 \mathrm{mV} \mathrm{s}^{-1}$.

Table 1. Electrochemical properties of 6-oxoverdazyl monomer $\mathbf{1 5}$ and polymer $\mathbf{1 6}$ and nitronyl nitroxide monomer $\mathbf{2 0}$ and polymer $21{ }^{a}$

\begin{tabular}{lccc}
\hline & $E_{1 / 2, \text { red }}(\mathrm{V}$ vs. Fc/Fc & $E_{1 / 2, \mathrm{ox}}\left(\mathrm{V}\right.$ vs. Fc/Fc $\left.{ }^{+}\right)$ & $E_{\text {cell }}(\mathrm{V})$ \\
\hline polymer 10 $^{16 \mathrm{~b}}$ & -1.35 & 0.25 & 1.60 \\
monomer 15 & -0.99 & 0.50 & 1.49 \\
polymer 16 & -0.96 & 0.49 & 1.45 \\
monomer 20 & -1.27 & 0.42 & 1.69 \\
polymer 21 & - & 0.44 & - \\
\hline
\end{tabular}

${ }^{a}$ Experiments were conducted in degassed mixtures of 50:50 v/v $\mathrm{CH}_{2} \mathrm{Cl}_{2} / \mathrm{CH}_{3} \mathrm{CN}$ containing approximately $1 \mathrm{mM}$ of monomer or polymer analyte and $0.1 \mathrm{M}\left[n \mathrm{Bu}_{4} \mathrm{~N}\right]\left[\mathrm{PF}_{6}\right]$ at scan rates of $250 \mathrm{mV} \mathrm{s}^{-1}$.

\section{Thin Films}

Two sets of thin films of varying thicknesses were obtained from solutions of polymers $\mathbf{1 6}$ and 21, respectively. These solutions were spun on glass substrates with pre-patterned ITO contacts, as discussed above. Panels (a) and (b) in Figure 5 offer a comparison of films at a comparable $(\sim 30 \mathrm{~nm})$ thickness. Both films appear to be disordered, probably due to the tendency of the polymeric chains to coil, with the formation of continuous layers and smooth surfaces. However, the superior smoothness of the film of 6-oxoverdazyl polymer 16 (with RMS roughness below 
$2.5 \mathrm{~nm}$ at less than $60 \mathrm{~nm}$ thickness, and no formation of grains and particulate) is evident. Irrespective of the growth process, extreme surface smoothness in amorphous thin films is typically linked to the ability of the growing species (i.e., polymer chains) to undergo surface diffusion during film formation (i.e., drying during spin coating). ${ }^{29}$ If this model is assumed, the superior smoothness of films of polymer $\mathbf{1 6}$ over polymer $\mathbf{2 1}$ likely results due to relatively weak interchain interactions in the drying films of polymer 16. The fact that the heteroatoms present in 6-oxoverdazyls are flanked by relatively large substituents and the heteroatoms in nitronyl nitroxides are readily accessible, further supports this assumption. Previous reports of very smooth thin films of related 6-oxoverdazyl polymers, ${ }^{16}$ including pinhole-free films below $10 \mathrm{~nm}$ thickness,${ }^{18}$ are consistent with the observations of the present study.

The smoothness of these polyradical thin films enabled the fabrication of sandwich-type devices with the architecture shown in Figure 5d. This architecture is identical to what was previously reported by Paquette et al. ${ }^{16 \mathrm{~b}}$ and Ezugwu et al. ${ }^{18}$ to demonstrate memory effects in the electrical properties of other forms of radical polymers. Memory effects in these devices were previously assigned ${ }^{18}$ to two distinct electrical transport regimes: extended-state transport, leading to an Ohmic current-voltage dependency, and localized-state transport leading to PooleFrenkel effects ${ }^{30}$ in which the current-voltage (I-V) characteristics are non-linear due to carrier trapping and detrapping induced by the external electric field. Generally speaking, as-grown thin films from both polymers $\mathbf{1 6}$ and $\mathbf{2 1}$ are in a low-conductivity state in which the electrical conductivity can be fitted consistently with Poole-Frenkel effects governed by the equation

$$
\mathrm{I}=\mathrm{S} \mathrm{V} \exp \left(\mathrm{A} \mathrm{V}^{1 / 2}\right)
$$


where $\mathrm{S}$ is the low-field, low-voltage sample conductance (depending on the depth of the traps as well as the specific transport process involved) and A depends on the dielectric constant of the medium as well as the measuring temperature. While a more complete investigation of the thickness and temperature effects on the electrical conductivity will be the subject of future studies, it is important to remark that the electrical conductance and conductivity are significantly lower (by a factor of $\sim 5 \times 10^{-3}$ ) in the 6-oxoverdazyl films, which is a strong indication of their amorphous nature, and consistent with their superior smoothness. Low conductivity persists until voltage is increased up to a critical value of $\mathrm{V} \sim 1.5 \mathrm{~V}$ (for polymer 16) or $\mathrm{V} \sim 2.0 \mathrm{~V}$ (for polymer 21) as demonstrated by the black arrows in Figures 5e and 5f, respectively. Then, a significantly higher conductivity is observed in both polymers, with an increase by a factor of $c a .2 .5$ in polymer $\mathbf{1 6}$ and $c a .4$ in polymer $\mathbf{2 1}$. A remarkably different behaviour is observed in the two samples, however: the high-conductivity state in 6-oxoverdazyl polymer films is still governed by eqn. (1) with minimal difference in the values of A and, therefore, similar properties of the background medium. Conversely, Ohmic behaviour, consistent with extended-state transport, and negligible values of A are observed for the nitronylnitroxide polymer thin films. These characteristics are indicative of critical differences in the transport properties of the two sets of polyradicals here investigated. A common denominator between the two sets of samples rest in the tunability of their transport properties as devices are reproducibly returned to the low-conductivity transport regimes when negative voltages below $\mathrm{V}$ $\sim-1.5 \mathrm{~V}$ are applied. Afterwards, multiple cycles between low- and high-conductivity can be reproducibly repeated on the same device. These effects may suggest that our radical polymers are suitable for resistive memory device applications, in analogy to what previously observed for another 6-oxoverdazyl radical polymer. ${ }^{18}$ 
(a)
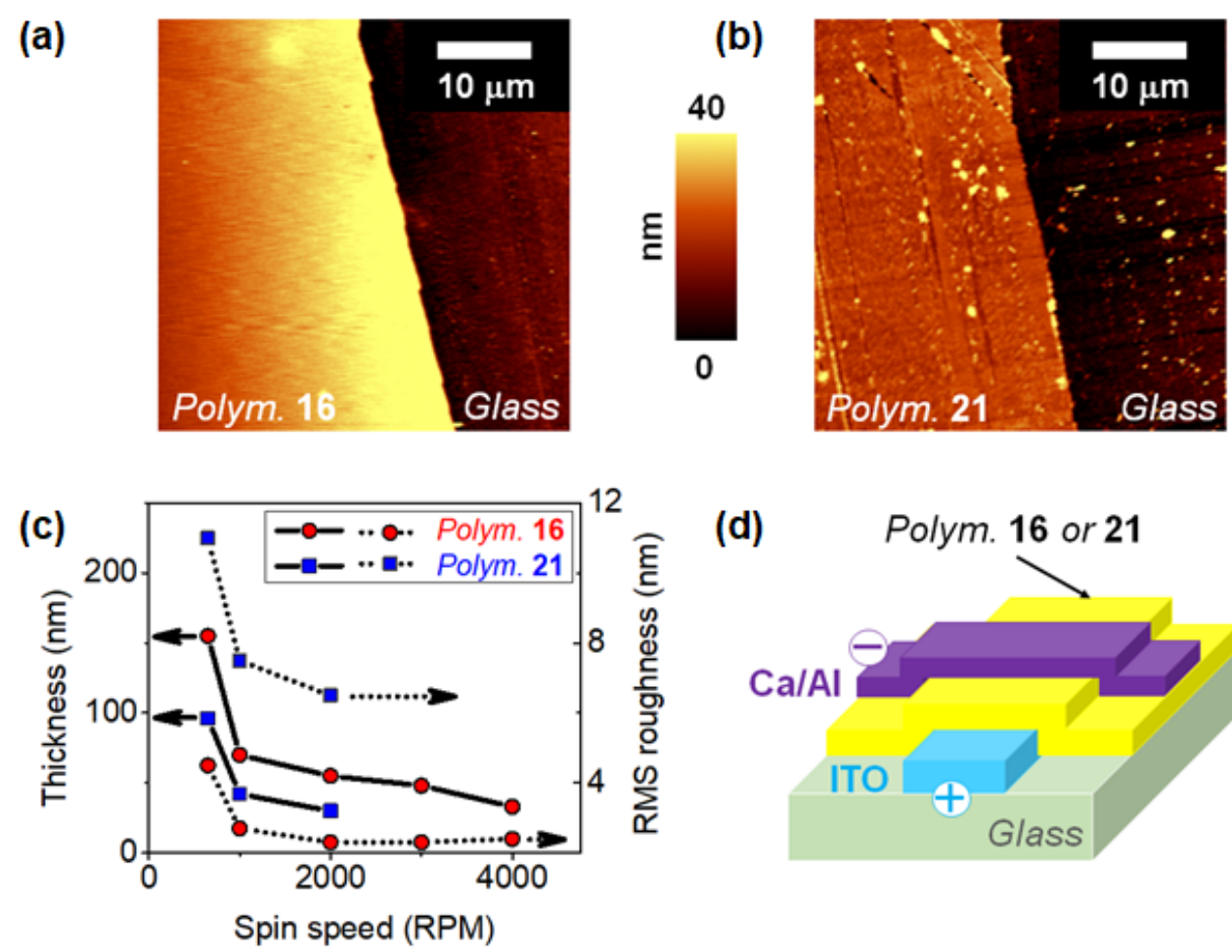

(d)
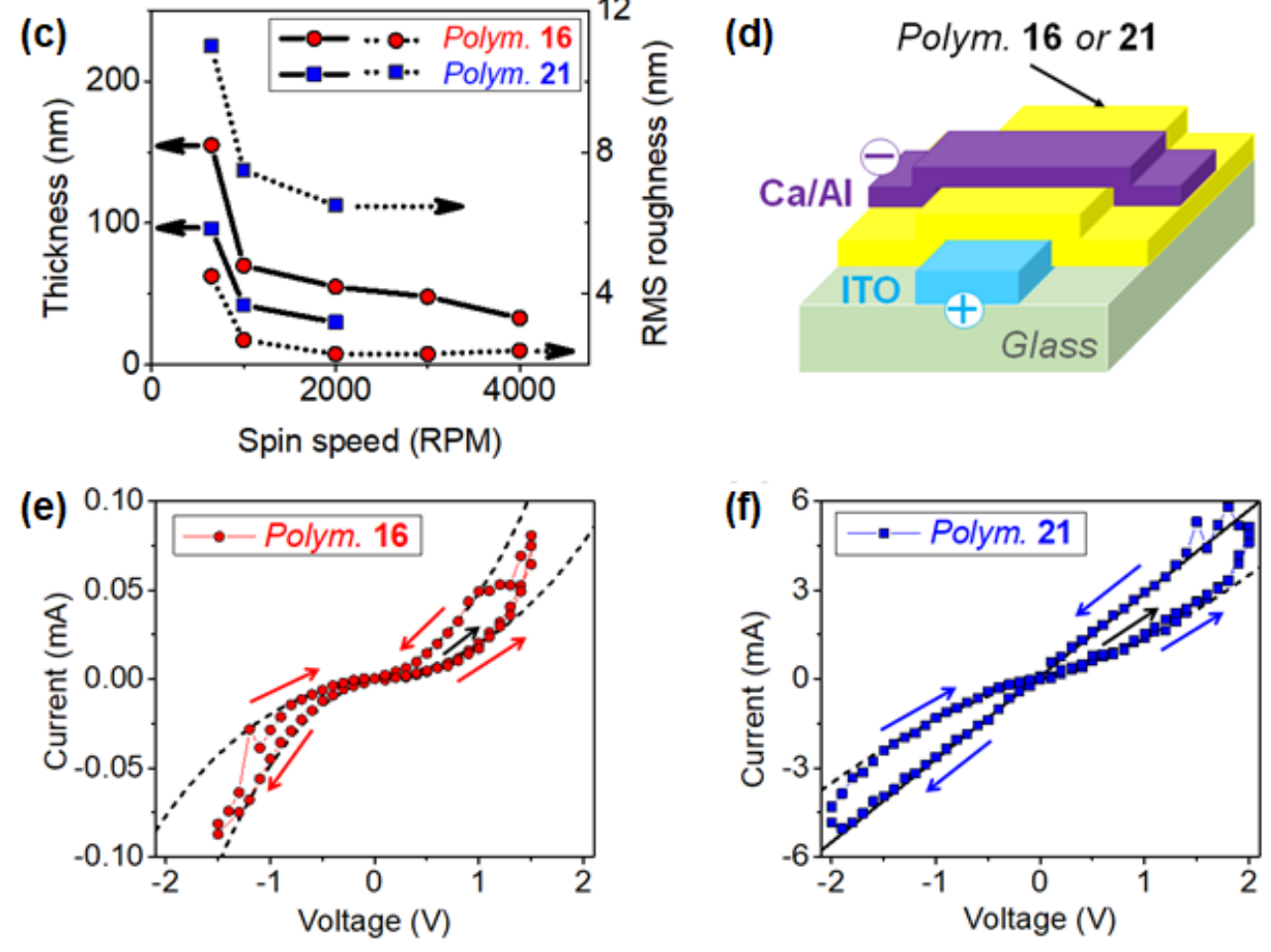

Figure 5. AFM images for (a) 6-oxoverdazyl polymer $\mathbf{1 6}$ and (b) nitronyl nitroxide polymer $\mathbf{2 1}$ at the lowest thicknesses ( $30 \mathrm{~nm} \pm 10 \%$ ) corresponding to 4000 RPM speed for polymer 16 and 2000 RPM spin speed for polymer 21. (c) Thicknesses and RMS roughness as a function of spin speed for these samples. (d) Device architectures used to test memory effects in the currentvoltage properties of (e) polymer 16 and (f) polymer 21. Dashed lines represent fits according to Poole-Frenkel equation. ${ }^{30}$ Solid line is a linear (Ohmic) current-voltage fit for polymer $\mathbf{2 1}$ in the high conductivity state.

\section{CONCLUSIONS}

In this work we have elaborated the structural diversity of radical polymers prepared by ROMP, specifically those containing 6-oxoverdazyl and nitronyl nitroxide radicals that have been 
traditionally underrepresented. We have studied the ROMP of our nitronyl nitroxide monomer in detail revealing that the reaction exhibits characteristics that are consistent with a living polymerization and offers excellent control over molecular weight and low dispersities. Optoelectronic properties were assessed using FT-IR, UV-vis absorption, and EPR spectroscopy and cyclic voltammetry revealing high radical contents that indicated that the ROMP mechanism was tolerant of the radicals employed. The monomers employed exhibited ambipolar redox properties, as did the 6-oxoverdazyl polymer studied. Thin films of the radical polymers exhibited memory effects in their electrical transport properties when current responses were studied as a function of the applied voltage, setting the stage for their future use in resistive memory applications. Profoundly different transport regimes in the two different types of polymers, 6-oxoverdazyls and nitronyl nitroxides, are anticipated.

\section{ACKNOWLEDGEMENTS}

This work was supported by the Natural Sciences and Engineering Research Council (NSERC) of Canada (G.F. \& J.B.G: SPG-P, 506356-2017), the Ontario Ministry of Research and Innovation (J.B.G.: ERA, ER-14-10-147; G.F.: LOF, 212442), and the Canadian Foundation for Innovation (J.B.G.: JELF, 33977).

\section{REFERENCES AND NOTES}

1 a) R. Gracia, D. Mecerreyes, Polym. Chem. 2013, 4, 2206-2214; b) N. Casado, G. Hernández, H. Sardon, D. Mecerreyes, Prog. Polym. Sci. 2016, 52, 107-135; c) R. Schroot, M. Jäger, U. S. Schubert, Chem. Soc. Rev. 2017, 46, 2754-2798. 
2 a) J. F. Mike, J. L. Lutkenhaus, J. Polym. Sci., Part B: Polym. Phys. 2013, 51, 468-480; b) J. Kim, J. H. Kim, K. Ariga, Joule 2017, 1, 739-768.

3 a) S. K. Goswami, C. J. McAdam, A. M. M. Lee, L. R. Hanton, S. C. Moratti, J. Mater. Chem. A 2013, 1, 3415-3420; b) Z. Song, H. Zhan, Y. Zhou, Angew. Chem. Int. Ed. 2010, 49, 8444-8448; c) J. Y. Oh, S. Rondeau-Gagné, Y.-C. Chiu, A. Chortos, F. Lissel, G.-J. N. Wang, B. C. Schroeder, T. Kurosawa, J. Lopez, T. Katsumata, J. Xu, C. Zhu, X. Gu, W.-G. Bae, Y. Kim, L. Jin, J. W. Chung, J. B.-H. Tok, Z. Bao, Nature 2016, 539, 411-415.

4 a) G. R. Whittell, M. D. Hager, U. S. Schubert, I. Manners, Nat. Mater. 2011, 10, 176-188; b) R. L. N. Hailes, A. M. Oliver, J. Gwyther, G. R. Whittell, I. Manners, Chem. Soc. Rev. 2016, 45, 5358-5407; c) M. Gallei, C. Rüttiger, Chem. Eur. J. 2018, 24, 10006-10021; d) Y. Wang, D. Astruc, A. S. Abd-El-Aziz, Chem. Soc. Rev. 2019, 48, 558-636.

5 J. Zhang, Y. P. Chen, K. P. Miller, M. S. Ganewatta, M. Bam, Y. Yan, M. Nagarkatti, A. W. Decho, C. Tang, J. Am. Chem. Soc. 2014, 136, 4873-4876.

6 a) K. Oyaizu, H. Nishide, Adv. Mater. 2009, 21, 2339-2344; b) E. P. Tomlinson, M. E. Hay, B. W. Boudouris, Macromolecules 2014, 47, 6145-6158; c) A. J. Wingate, B. W. Boudouris, J. Polym. Sci., Part A: Polym. Chem. 2016, 54, 1875-1894; d) K. Zhang, M. J. Monteiro, Z. Jia, Polym. Chem. 2016, 7, 5589-5614; e) K. A. Hansen, J. P. Blinco, Polym. Chem. 2018, 9, 1479-1516.

7 a) T. Suga, H. Ohshiro, S. Sugita, K. Oyaizu, H. Nishide, Adv. Mater. 2009, 21, 1627-1630; b) P. Nesvadba, L. Bugnon, P. Maire, P. Novák, Chem. Mater. 2010, 22, 783-788.

8 a) A. C. Arsenault, D. P. Puzzo, I. Manners, G. A. Ozin, Nat. Photon. 2007, 1, 468-472; b) T. F. Otero, J. G. Martinez, J. Arias-Pardilla, Electrochim. Acta 2012, 84, 112-128. 
9 a) Y. Ma, W.-F. Dong, M. A. Hempenius, H. Möhwald, G. J. Vancso, Nat. Mater. 2006, 5, 724-729; b) R. H. Staff, M. Gallei, M. Mazurowski, M. Rehahn, R. Berger, K. Landfester, D. Crespy, ACS Nano 2012, 6, 9042-9049.

10 a) T. Janoschka, M. D. Hager, U. S. Schubert, Adv. Mater. 2012, 24, 6397-6409; b) S. Muench, A. Wild, C. Friebe, B. Häupler, T. Janoschka, U. S. Schubert, Chem. Rev. 2016, $116,9438-9484$.

11 T. Janoselika, N. Martin, U. Martin, C. Friebe, S. Morgenstern, H. Hiller, M. D. Hager, U. S. Schubert, Nature 2015, 527, 78-81.

12 a) Y. Yonekuta, K. Susuki, K. Oyaizu, K. Honda, H. Nishide, J. Am. Chem. Soc. 2007, 129, 14128-14129; b) M.-K. Hung, Y.-H. Wang, C.-H. Lin, H.-C. Lin, J.-T. Lee, J. Mater. Chem. 2012, 22, 1570-1577; c) T. W. Kemper, R. E. Larsen, T. Gennett, J. Phys. Chem. C 2015, 119, 21369-21375; d) Y. Li, Z. Jian, M. Lang, C. Zhang, X. Huang, ACS Appl. Mater. Interfaces 2016, 8, 17352-17359; e) S. H. Sung, N. Bajaj, J. F. Rhoads, G. T. Chiu, B. W. Boudouris, Org. Electron. 2016, 37, 148-154; f) K. Zhang, Y. Hu, L. Wang, J. Fan, M. J. Monteiro, Z. Jia, Polym. Chem. 2017, 8, 1815-1823; g) L. Zheng, S. Mukherjee, K. Wang, M. E. Hay, B. W. Boudouris, X. Gong, J. Mater. Chem. A 2017, 5, 23831-23839; h) H. J. Martin, B. K. Hughes, W. A. Braunecker, T. Gennett, M. D. Dadmun, J. Mater. Chem. A 2018, 6, 15659-15667; i) H. Jia, T. Quan, X. Liu, L. Bai, J. Wang, F. Boujioui, R. Ye, A. Vlad, Y. Lu, J.-F. Gohy, Nano Energy 2019, 64, 103949; j) A. Gopinath, A. Sultan Nasar, Polymer 2019, 178, 121601; k) Y. Joo, S. Mukherjee, B. W. Boudouris, ACS Appl. Polym. Mater. 2019, 1, 204-210.

13 S. Wang, F. Li, A. D. Easley, J. L. Lutkenhaus, Nat. Mater. 2019, 18, 69-75. 
14 Y. Joo, V. Agarkar, S. H. Sung, B. M. Savoie, B. W. Boudouris, Science 2018, 359, 1391-1394.

15 a) A. Fujii, T. Ishida, N. Koga, H. Iwamura, Macromolecules 1991, 24, 1077-1082; b) Y. Miura, Y. Ushitani, M. Matsumoto, K. Inui, Y. Teki, T. Takui, K. Itoh, Mol. Cryst. Liq. Cryst. 1993, 232, 135-142; c) H. Nishide, Y. Hozumi, T. Nii, E. Tsuchida, Macromolecules 1997, 30, 3986-3991; d) T. Suga, S. Sugita, H. Ohshiro, K. Oyaizu, H. Nishide, Adv. Mater. 2011, 23, 751-754; e) K. Oyaizu, T. Sukegawa, H. Nishide, Chem. Lett. 2011, 40, 184-185; f) T. Sukegawa, A. Kai, K. Oyaizu, H. Nishide, Macromolecules 2013, 46, 1361-1367.

16 a) J. T. Price, J. A. Paquette, C. S. Harrison, R. Bauld, G. Fanchini, J. B. Gilroy, Polym. Chem. 2014, 5, 5223-5226; b) J. A. Paquette, S. Ezugwu, V. Yadav, G. Fanchini, J. B. Gilroy, J. Polym. Sci., Part A: Polym. Chem. 2016, 54, 1803-1813.

17 R. G. Hicks, Stable radicals : fundamentals and applied aspects of odd-electron compounds, Wiley, Chichester, UK, 2010.

18 S. Ezugwu, J. A. Paquette, V. Yadav, J. B. Gilroy, G. Fanchini, Adv. Electron. Mater. 2016, $2,1600253$.

19 C. W. Johnston, S. D. J. McKinnon, B. O. Patrick, R. G. Hicks, Dalton Trans. 2013, 42, 16829-16836.

20 L. Ren, J. Zhang, X. Bai, C. G. Hardy, K. D. Shimizu, C. Tang, Chem. Sci. 2012, 3, $580-583$.

21 S. Shimono, R. Tamura, N. Ikuma, T. Takimoto, N. Kawame, O. Tamada, N. Sakai, H. Matsuura, J. Yamauchi, J. Org. Chem. 2004, 69, 475-481.

22 M. S. Sanford, J. A. Love, R. H. Grubbs, Organometallics 2001, 20, 5314-5318. 
23 S. Stoll, A. Schweiger, J. Magn. Res. 2006, 178, 42-55.

24 R. E. Del Sesto, A. M. Arif, J. S. Miller, Inorg. Chem. 2000, 39, 4894-4902.

25 S. M. Barbon, P. Gobbo, W. Luo, J. T. Price, M. C. Biesinger, M. S. Workentin, J. B. Gilroy, SYNLETT 2016, 27, 304-308.

26 C. Nicolas, L. Fontaine, V. Montembault, Polym. Chem. 2019, 10, 5487-5497.

27 Z. Wang, J. A. Paquette, V. N. Staroverov, J. B. Gilroy, T.-K. Sham, J. Phys. Chem. A 2019, $123,323-328$.

28 J. B. Gilroy, S. D. J. McKinnon, B. D. Koivisto, R. G. Hicks, Org. Lett. 2007, 9, 4837-4840.

29 a) C. Casiraghi, A. C. Ferrari, R. Ohr, A. J. Flewitt, D. P. Chu, J. Robertson, Phys. Rev. Lett. 2003, 91, 226104; b) C. Casiraghi, A. C. Ferrari, J. Robertson, Diam. Relat. Mater. 2005, 14, 913-920.

30 S. M. Sze, Physics of Semiconductor Devices, 2nd ed., Wiley, New York, 1998. 


\section{TABLE OF CONTENTS ENTRY}

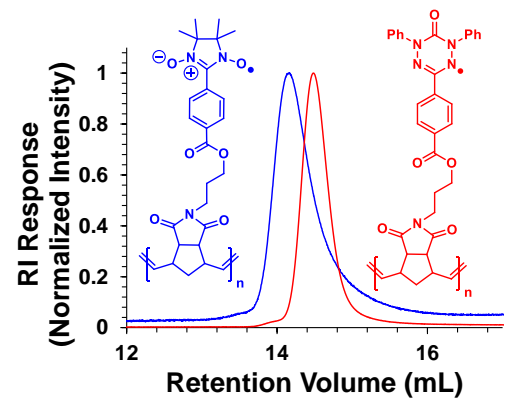

Polymers containing pendant 6-oxoverdazyl or nitronyl nitroxide radicals have been prepared by ring-opening metathesis polymerization. Their film-forming properties and redox properties render them excellent candidates for resistive memory applications. 